\section{Como nascem os clássicos}

Luiz Carlos JACKSON. A tradição esquecida: Os parceiros do Rio Bonito e a sociologia de Antonio Candido. Belo Horizonte/São Paulo, Ed. da UFMG/Fapesp. 2002. 234 páginas.

\section{Enio Passiani}

Originalmente escrito como dissertação de mestrado, o trabalho de Luiz Carlos Jackson nos oferece muito mais do que, habitualmente, uma pesquisa acadêmica dessa natureza pode sugerir, pois revela as sutilezas e a grandeza da obra Os parceiros do Rio Bonito, de Antonio Candido, ao responder a duas questões que aparentemente, e apenas aparentemente, soam ingênuas ou óbvias: por que Os parceiros constituem um clássico da sociologia brasileira? E por que tal obra permaneceu num estado de quase dormência por um certo lapso de tempo?

A própria organização do livro procura responder a tais perguntas, uma vez que as duas partes que o compõem em nenhum momento se antagonizam, mas, ao contrário, entremeiam-se, dialogam e se completam. A primeira refere-se à análise propriamente dita de Os parceiros, enquanto a segunda apresenta as entrevistas que o pesquisador realizou - com o próprio Antonio Candido, além de Edgard Carone, Décio de Almeida Prado e José de Souza Martins. Vale ressaltar a honestidade intelectual do autor, bem como sua ousadia, ao conservar as entrevistas no livro, pois elas permitem ao leitor perceber o quanto foram importantes para o redirecionamento da pesquisa em algumas ocasiões; já, em outras, confirmam as interpretações realizadas e até mesmo fazem o leitor desconfiar de que algumas respostas ainda precisam ser um pouco mais buriladas.

Jackson começa a responder à primeira pergunta de uma maneira extremamente clara, para, em seguida, aprofundar seus argumentos. O primeiro passo é esclarecer qual o objeto e os objetivos mais imediatos e explícitos de Candido: o estudo das relações possíveis entre a obtenção dos meios materiais de vida e as formas de sociabilidade correspondentes; nesse sentido, as necessidades possuem também um caráter social, pois a vida e a sobrevivência de um determinado agrupamento humano depende do equilibrio estabelecido entre tais necessidades e os recursos que o grupo dispõe para satisfazê-las. Destarte, para cada cultura há, em cada momento, certos mínimos abaixo dos quais não é possível haver equilíbrio: a certos "mínimos vitais" de alimentação e abrigo correspondem certos "mínimos sociais" de organização para obtê-los e garantir a própria sociabilidade do grupo. Por isso, a sociologia proposta por Candido é chamada de "'sociologia dos meios de subsistência', buscando interpretar todas as dimensões da vida social, a partir da alimentação." (p. 53). Em seguida, Jackson nos mostra que o estudo sobre a precariedade do mundo material caipira, marcada por uma economia de subsistência, não é tão circunstancial ou extremamente particularizada como pode parecer, já que a análise dos parceiros de Bofete tem como pano de fundo o processo mais amplo de modernização do país, caracterizado pela intensa industrialização e a formação da sociedade de classes. De acordo com Jackson:

\begin{abstract}
A interpretação de Antonio Candido integra essas duas questões a partir da análise da situação de crise da cultura caipira, em face da expansão da economia capitalista. No grupo de parceiros estudado, o autor busca diferenciar os fatos que indicam persistência de padrões tradicionais dos que apontam para a alteração (p. 59).
\end{abstract}

A expansão da economia capitalista causa grande impacto na cultura caipira, provocando sua crise e obrigando-a à elaboração de um novo "ajuste ecológico" para justamente evitar, ou ao menos retardar, sua derrocada. O livro de Candido é herdeiro de uma tradição que remonta a Euclides da Cunha, pois retoma e aprofunda uma tese presente em Os sertões, a saber, a existência e a convivência de dois Brasis, o do litoral, industrializado e moderno, e o do interior, agrário e atrasado, que sobrevive, embora ameaçado, de modo relativamente autônomo.

Pressionada pela modernização, a cultura caipira "caminha para o fim inevitável" mas é ainda capaz de criar "formas de resistência", oscilando, tal como os movimentos de um pêndulo, entre a mudança cultural e a estabilidade. A análise 
da tensão caracteriza certas escolhas temáticas de Candido, como podemos perceber no artigo "Dialética da malandragem", publicado posteriormente e que tem como foco a sociedade urbana carioca do século XIX. A alternância entre estabilidade e instabilidade observada no mundo caipira diz respeito, no fundo, às condições históricas da mudança ao longo da formação da sociedade brasileira e ao seu ritmo lento, no qual convivem várias temporalidades, marcado pelo balanço entre continuidade, ajuste e ruptura, pelo jogo entre transformação e permanência.

Jackson sublinha que Candido tem como preocupação entender não apenas a cultura e a sociabilidade caipiras em Bofete, mas as peculiaridades da formação social e histórica de São Paulo e do Brasil. Trata-se de uma análise que parte de uma visada microscópica, centrada no interior do país, e acaba oferecendo um rendimento macroscópico, ou seja, uma "interpretação ampla da sociedade brasileira (p. 50) que leva em consideração suas especificidades históricas. Não há como não apontar a importância da história no pensamento de Antonio Candido, para quem os fatos sociais só podem ser apreendidos como algo dinâmico, no interior de sua dimensão histórica compreender o presente exige a investigação do passado. Mais uma vez, Candido retoma uma certa tradição do pensamento brasileiro ao sinalizar uma interpretação mais abrangente de nossa formação social a partir de um estudo aparentemente restrito, tal como ocorre em Casa grande $\varepsilon$ senzala, Raízes do Brasil e Formação do Brasil contemporâneo - obras das quais são retomados igualmente o estilo literário e o ensaio de caráter histórico-sociológico que caracterizou a produção de Gilberto Freyre, Sérgio Buarque de Holanda e Caio Prado. A inter-relação entre estilo literário e imaginação sociológica presente em Antonio Candido remete à própria gênese do pensamento social brasileiro, com raízes na literatura, que na falta das ciências sociais constituídas e institucionalizadas serviu aos intelectuais como o principal instrumento de reflexão sobre nossa realidade social. Tal entrelaçamento é apropriadamente explicitado por Luiz Carlos Jackson ao discutir o desenvolvimento quase paralelo de duas obras capitais de Candido: Os parceiros do Rio Bonito e
Formação da literatura brasileira, e, mais do que isso, a correspondência existente entre elas, a maneira como convergem para um mesmo tema, qual seja, o processo de formação da sociedade nacional.

A capacidade que Antonio Candido tem de retomar a tradição de nosso pensamento social e relacioná-la de modo apropriado com as mais variadas fontes teóricas está vinculada à metodologia adotada. Jackson mostra quanto o autor evitava os apriorismos do método, receoso de ser aprisionado por um "rigorismo metodológico" que paralisaria a investigação. O ponto de partida de qualquer estudo, para Antonio Candido, não é a teoria, mas o concreto, isto é, o caminho que o cientista percorre vai do fato concreto para a teoria, por conseguinte, o método de investigação se constrói ao longo da própria pesquisa, durante a qual a sensibilidade do pesquisador está sempre presente. Daí sua "perspectiva integrativa", que procura a síntese entre correntes teóricas e disciplinas e consegue alinhavar de maneira proveitosa, na composição de Os parceiros, a Antropologia, a História e a Sociologia. Executar tal combinação permite-lhe recusar a definição mais tradicional de "comunidade" e propor, no seu lugar, o conceito de "bairro", elaboração original de Candido e fundamental para a análise.

O pensamento de Antonio Candido, portanto, é radical em muitos sentidos, desde a heterodoxia metodológica, bastante incomum no ambiente acadêmico da época, passando pelo próprio estilo de análise, até os desafios éticos e políticos que o autor se coloca. Candido exerce o que poderíamos chamar de "saber militante", aquele que não descarta uma posição política. Sua análise dedica-se a um problema social e contém uma proposta política: recuperar a voz dos "marginalizados da colonização" e defender a inclusão do caipira num mundo que se moderniza por meio da reforma agrária - eis o fio que o liga ao "pensamento radical" de autores como Joaquim Nabuco, Manuel Bonfim e Sérgio Buarque de Holanda.

Segundo Jackson, Candido recolhe toda uma tradição de nosso pensamento social, mas, ao mesmo tempo, atualiza essa tradição e incorpora a ela novos elementos, apresentando um novo estilo de se fazer sociologia e uma linguagem socio- 
lógica, o que torna Os parceiros um clássico e uma referência para os estudos sobre o mundo caipira, que vai influenciar gerações futuras de talentosos pesquisadores, entre eles Maria Isaura Pereira de Queiroz, Maria Sylvia Carvalho Franco, José César Gnaccarini e José de Souza Martins.

Mas, se o livro de Antonio Candido ocupa lugar central na sociologia brasileira, resta ainda saber por que sua recepção foi tão morna logo após seu lançamento e mesmo alguns anos depois. Nesse ponto, arrisco dizer que Jackson titubeia em sua explicação, pois parece simplesmente aceitar a resposta oferecida por José de Souza Martins. De acordo com este último, o fato de o livro ter sido publicado dez anos após a defesa da tese (que ocorrera em 1954), foi decisivo para sua pequena repercussão imediata, uma vez que o clima político da época orientou ideologicamente vários trabalhos nas ciências sociais brasileiras do período. Situação contornada posteriormente, em décadas mais recentes, quando a recepção do livro tem sido cada vez mais favorável, não apenas em estudos sobre o mundo rural, mas também como referência metodológica obrigatória.

Não há equívoco algum na resposta de Martins aceita por Luiz Carlos Jackson. Contudo, ela pode ser ainda mais problematizada. Vale a pena perguntar se uma sociologia do campo intelectual não seria capaz de fornecer perspectivas outras, como, por exemplo, retomar com mais cuidado o momento da cristalização da sociologia como disciplina científica, o que implicava certas exigências institucionais que provocavam dúvidas sobre um trabalho tão eclético quanto o de Cândido.

Quiçá, indagar se a migração de uma região do campo - a sociologia - para outra - a crítica literária - afetou, pelo menos parcialmente, a recepção do livro, em razão de certos embates em que tais disciplinas poderiam se ver envolvidas em torno da disputa pela interpretação supostamente mais legítima da formação da sociedade brasileira; uma sociologia que perscrutasse nosso campo intelectual talvez pudesse até explicar como a posição hegemônica desfrutada por Antonio Candido já há algum tempo, com todo seu reconhecimento, consagração e prestígio, gerou certas disposições mnemônicas que lhe permitiram reconstruir seu passado, reelaborar e ressignificar suas memórias, transformando a subjetividade, essa espécie de ruído que atrapalha a análise mais objetiva e que permeia as entrevistas - fato reconhecido por Jackson logo na introdução de seu trabalho -, em material para a análise sociológica. Pois não deixa de ser curioso, inquietante mesmo, como um intelectual dedica todo o início de sua carreira acadêmica a uma dada disciplina por meio da atividade docente, da publicação de artigos, defesa de tese e a escrita de um clássico, Os parceiros, para depois afirmar que se interessa pela sociologia "como ponto de vista", como "visão de mundo". Um certo desinteresse que Antonio Candido demonstra posteriormente pela sociologia, quando já ocupa posição destacada na crítica literária nacional, pode ser um fator que tenha influenciado na repercussão de Os parceiros do Rio Bonito.

A hesitação de Jackson em avançar algumas questões não elimina, tampouco diminui, a importância de seu trabalho. Ele nos diz, com todas as letras, por que Os parceiros do Rio Bonito é um clássico e como ele nasce. Jackson nos convida a ler e a reler esta obra fundamental do pensamento social brasileiro e tornarmo-nos seu parceiro na leitura de um livro que à medida que envelhece, torna-se cada vez mais novo. Para usar um neologismo à la Guimarães Rosa - outro grande autor que se voltou para os nossos grandes sertões um livro que insiste em "rejuvelhecer".

\section{ENIO PASSIANI é mestre em sociologia pela Universidade de São Paulo e professor universitário.}

